\title{
Studies on Chitin. V. Formylation, Propionylation, and Butyrylation of Chitin
}

\author{
Katsuaki KAIFU,* Norio NisHI,* Takashi KomAI, ${ }^{*}$ \\ Seiichi TOKURA,* and Oyin SOMORIN** \\ *Department of Polymer Science, Faculty of Science, Hokkaido University, \\ Nishi 8-chome, Kita 10-jo, Kita-ku, Sapporo 060, Japan. \\ **Chemistry Department, University of Lagos, Lagos, Nigeria.
}

(Received June 30, 1980)

\begin{abstract}
Variously substituted propionylchitin, and butyrylchitin were prepared using the corresponding carboxylic acid, carboxylic anhydride or their mixture in methanesulfonic acid at low temperatures. Formylchitin derivatives with different degrees of formylation were prepared from a formic acid-methanesulfonic acid mixture. Highly substituted butyrylchitin is easily soluble in common organic solvents such as dioxane, tetrahydrofuran, acetone, acetonitrile, dimethylformamide, acetic acid, and methanol in addition to acidic solvents such as formic acid and dichloroacetic acid. Other acylchitins are soluble only in acidic solvents. The viscometric behavior of a chitin solution in methanesulfonic acid and the infrared absorption spectra of the acylchitin derivatives were also investigated.
\end{abstract}

KEY WORDS Chitin / Formylchitin / Propionylchitin / Butyrylchitin / Methanesulfonic Acid / Carboxylic Anhydride / Solubility / Infrared Absorption Spectra / Viscosity /

Chitin, a principal component of the supporting structure of several living organisms such as fungi and anthropods, is one of the mucopolysaccharides having the repeating structural unit of 2-acetamido2-deoxy- $\beta$-D-glucose. This polysaccharide, therefore, can be regarded as an analogue of cellulose, with an acetylamino group instead of the C-2 hydroxyl group. However, the chemical or physical properties are quite different from those of cellulose despite the similarity in their chemical structures. For instance, chitin is considerably more resistant to chemical reagents because of its strong micelle structure, and hence, research on chitin is limited; it has not yet been regarded as a useful natural resource compared with other polysaccharides such as cellulose or starch.

Recently, we reported that methanesulfonic acid can be successfully employed for the acylation of chitin, as an effective catalyst and a suitable solvent. ${ }^{1}$ Variously substituted acetylchitin ${ }^{1}$ and benzoylchitin ${ }^{2}$ derivatives were prepared by this method. The acetylchitin obtained by this procedure was successfully converted into fine fibers with a high Young's modulus and good dyeability. ${ }^{3}$ Recently, diacetylchitin was found to have the property of being a good blood anticoagulant in contrast to chitin. Thus, through a chemical modification of chitin, its properties can be improved as a biomedical material. ${ }^{4}$ Also, highly benzoylated chitin is easily soluble in benzyl alcohol and dimethylsulfoxide in addition to acidic solvents such as formic acid or dichloroacetic acid. ${ }^{2}$ Chemically modified chitin derivatives having good solubility in organic solvents are therefore desirable in for promoting its usefulness and widen the scope of its industrial and other practical applications. The introduction of acyl groups with longer aliphatic chains to the chitin molecule can improve its solubility in organic solvents, since acetylation of chitin increases its solubility property in formic acid. Also, it will be interesting to investigate the relationship between the effect of the acylating group and the biomedical properties of the acylated chitin derivatives.

The preparation and properties of formylchitin, propionylchitin, and butyrylchitin derivatives are 
reported in this paper.

\section{EXPERIMENTAL}

The elemental analyses for chitin derivatives were carried out by means of a Yanagimoto $\mathrm{CHN}$ Corder, Model MT-2. The theoretical values are calculated assuming that a non-substituted or mono-substituted $N$-acetylglucosamine residue binds half a mole of water, and a di-substituted residue has no bound water. ${ }^{1}$ The infrared absorption spectra were measured with a JASCO infrared spectrophotometer, Model A-302, by the $\mathrm{KBr}$ pellet method.

\section{Chitin}

Powdered chitin of crab shell (Alaska King Crab) was obtained from Nippon Suisan Co. Ltd.

Anal. Calcd for $\mathrm{C}_{8} \mathrm{H}_{13} \mathrm{NO}_{5} \cdot 1 / 2 \mathrm{H}_{2} \mathrm{O}: \mathrm{C}, 45.28 \%$; $\mathrm{H}, 6.60 \%$; N, $6.60 \%$. Found: $\mathrm{C}, 44.96 \%$; $\mathrm{H}, 6.50 \%$; $\mathrm{N}, 6.57 \%$.

\section{Reagents}

Methanesulfonic acid, formic acid, propionic acid, $n$-butyric acid, propionic anhydride and $n$ butyric anhydride were all purchased from Wako Pure Chemical Industries, Ltd. and they were used without further purification.

\section{Measurement of Viscosity}

Viscosity was measured with an Ostwald-type viscometer. A $100 \mathrm{mg}$ portion of chitin was dissolved in $10 \mathrm{ml}$ of methanesulfonic acid and $8 \mathrm{ml}$ aliquot were immediately displaced in the viscometer. The time course of viscosity change was measured for $6 \mathrm{~h}$ at $25^{\circ} \mathrm{C}$ or $40^{\circ} \mathrm{C}$. The time course at $0^{\circ} \mathrm{C}$ was followed by measuring the viscosity at $25^{\circ} \mathrm{C}$ after melting the half frozen mixture stored at $0^{\circ} \mathrm{C}$.

\section{Preparation of Propionylchitins}

(a) Methanesulfonic Acid Procedure. Chitin powder $(3.0 \mathrm{~g})$ was added to the mixture of methanesulfonic acid $(12 \mathrm{ml})$, propionic anhydride, and propionic acid with stirring at $0^{\circ} \mathrm{C}$. The total amount of propionic anhydride and propionic acid was generally $18 \mathrm{ml}$. The mixture was stirred for $2 \mathrm{~h}$ at $0^{\circ} \mathrm{C}$ and then the resulting gel was stored at $-20^{\circ} \mathrm{C}$ overnight. The product was precipitated with a large quantity of cracked ice, filtered, and then washed with water. This was immediately suspended in distilled water, neutralized to $\mathrm{pH} 7.0$ with ammonium hydroxide, and then boiled for a few minutes to remove any traces of acid. Acylated chitin was collected by filtration, washed with distilled water, and dried in vacuo. Propionylchitin at varying degrees of propionylation was obtained by changing the amounts of propionic anhydride and propionic acid.

(b) From Alkali Chitin. Alkali chitin (27.0 g), which was prepared from chitin $(10 \mathrm{~g})$ as described previously, ${ }^{1}$ was placed in a separatory funnel. The system was evacuated and the mixture was frozen at $-20^{\circ} \mathrm{C}$ overnight. Propionic anhydride $(20 \mathrm{ml})$ was introduced with the aid at an internally reduced pressure, and shaken vigorously on cooling with ice. The mixture was maintained at room temperature for $24 \mathrm{~h}$ with occasional shaking. The product, precipitated with ethanol, was collected by filtration. It was suspended in distilled water and was stirred well. The propionylchitin was filtered, washed with water and ethanol, and then dried in vacuo: yield $9.5 \mathrm{~g}(86 \%)$. It was found by elemental analysis that $0.4 \mathrm{~mol}$ of $\mathrm{OH}$ groups per residue was propionylated (0.4 propionylchitin).

Anal. Calcd for $\left[\mathrm{C}_{8} \mathrm{H}_{11} \mathrm{NO}_{3}(\mathrm{OH})\left(\mathrm{OCOC}_{2} \mathrm{H}_{5}\right)\right.$. $\left.1 / 2 \mathrm{H}_{2} \mathrm{O}\right]_{0.4}\left[\mathrm{C}_{8} \mathrm{H}_{13} \mathrm{NO}_{5} \cdot 1 / 2 \mathrm{H}_{2} \mathrm{O}\right]_{0.6}: \mathrm{C}, 47.09 \% ; \mathrm{H}$, $6.70 \%$; N, $5.97 \%$. Found: C, $47.21 \%$; H, $6.56 \% ; \mathrm{N}$, $6.47 \%$.

\section{Preparation of Butyrylchitins}

Chitin was converted into variously substituted butyrylchitins using methanesulfonic acid, butyric anhydride, and butyric acid by the same procedure as in the case of propionylchitin.

\section{Preparation of Formylchitins}

(a) Methanesulfonic acid Procedure. Variously formylated chitins were also prepared in methanesulfonic acid by the same procedures used for propionylchitin or butyrylchitin except that only formic acid was employed without formic anhydride.

(b) Sulfuric Acid Procedure. Chitin powder $(3.0 \mathrm{~g})$ was added to the mixture of concentrated sulfuric acid $(12 \mathrm{ml})$ and formic acid $(18.0 \mathrm{ml}, 34$ equiv mol to $N$-acetylglucosamine residue) with stirring at $0^{\circ} \mathrm{C}$. The mixture was stirred at $0^{\circ} \mathrm{C}$ for $2 \mathrm{~h}$ and stored at $-20^{\circ} \mathrm{C}$ overnight. The formylchitin was worked up by the same procedures used in the preparation of propionylchitin by methane- 
sulfonic acid method: yield $3.3 \mathrm{~g}(96 \%)$. It was found by elemental analysis that $1.1 \mathrm{~mol}$ of $\mathrm{OH}$ groups per residue were formylated (1.1 formylchitin).

Anal. Calcd for $\left[\mathrm{C}_{8} \mathrm{H}_{11} \mathrm{NO}_{3}(\mathrm{OCOH})_{2}\right]_{0.1}$ $\left[\mathrm{C}_{8} \mathrm{H}_{11} \mathrm{NO}_{3}(\mathrm{OH})(\mathrm{OCOH}) \cdot 1 / 2 \mathrm{H}_{2} \mathrm{O}\right]_{0.9}: \mathrm{C}, 45.14 \%$; $\mathrm{H}, 5.79 \%$;, $5.79 \%$. Found: $\mathrm{C}, 45.11 \% ; \mathrm{H}$, $5.73 \% ; \mathrm{N}, 5.74 \%$.

\section{RESULTS AND DISCUSSION}

\section{Preparation of Propionyl and Butyrylchitins}

Previously, we reported an effective procedure for acetylating chitin, using methanesulfonic acid. ${ }^{1}$ Chitin is easily soluble in this solvent even at low temperatures and its acidity is strong enough to be used as the catalyst in esterification. Completely acetylated chitin (diacetylchitin) was easily obtained with an acetic anhydride-methanesulfonic acid mixture and the degree of acetylation could be regulated by controlling the acetic anhydride-acetic acid ratio.

The preparation of variously propionylated chitin derivatives was performed in a similar way. The relationship between the degree of propionylation and the reaction conditions are listed in Table I. All acylation reactions were carried out at low temperatures to prevent decomposition of the chitin molecule as will be discussed later. The reaction in the methanesulfonic acid-propionic anhydride mix-

Table I. Propionylation of chitin in a methanesulfonic acid-propionic anhydride-propionic acid mixture

\begin{tabular}{|c|c|c|c|c|c|c|c|c|c|c|}
\hline \multirow{2}{*}{$\begin{array}{c}\text { Sample } \\
\text { No. }\end{array}$} & \multirow{2}{*}{$\begin{array}{c}\begin{array}{c}\text { Propionic } \\
\text { anhydride }\end{array} \\
\text { ml (equiv } \text { mol }^{\mathrm{b}} \text { ) }\end{array}$} & \multirow{2}{*}{$\begin{array}{c}\begin{array}{c}\text { Propionic } \\
\text { acid }^{\mathrm{a}}\end{array} \\
\mathrm{ml}\end{array}$} & \multirow{2}{*}{$\begin{array}{c}\text { Degree of } \\
\text { propionylation }^{c}\end{array}$} & \multirow{2}{*}{$\begin{array}{c}\text { Yield } \\
\%\end{array}$} & \multicolumn{3}{|c|}{ Found $/ \%$} & \multicolumn{3}{|c|}{ Calcd $/ \%$} \\
\hline & & & & & $\mathrm{C}$ & $\mathrm{H}$ & $\mathrm{N}$ & $\mathrm{C}$ & $\mathrm{H}$ & $\mathrm{N}$ \\
\hline 1 & - & 18.0 & 1.0 & 92 & 48.91 & 6.61 & 5.16 & 49.25 & 6.76 & 5.22 \\
\hline 2 & $0.9(0.5)$ & 17.1 & 1.0 & 92 & 49.26 & 6.65 & 5.36 & 49.25 & 6.76 & 5.22 \\
\hline 3 & $1.8(1.0)$ & 16.2 & 1.0 & 87 & 49.62 & 6.60 & 5.57 & 49.25 & 6.76 & 5.22 \\
\hline 4 & $3.6(2.0)$ & 14.4 & 1.0 & 95 & 49.29 & 6.65 & 5.27 & 49.25 & 6.76 & 5.22 \\
\hline 5 & $7.2(4.0)$ & 10.8 & 1.5 & 80 & 51.16 & 6.55 & 4.65 & 51.45 & 6.74 & 4.80 \\
\hline 6 & $10.8(6.0)$ & 7.2 & 1.6 & 91 & 51.57 & 6.73 & 4.55 & 51.85 & 6.73 & 4.72 \\
\hline 7 & $18.0(9.9)$ & - & 1.9 & 85 & 52.50 & 6.74 & 4.30 & 52.97 & 6.72 & 4.51 \\
\hline 8 & $0.9(0.5)$ & - & 0.1 & 49 & 45.49 & 6.64 & 6.21 & 45.77 & 6.66 & 6.43 \\
\hline
\end{tabular}

a Amount of the reagents per $3 \mathrm{~g}$ of chitin. All reactions were carried out by stirring at $0^{\circ} \mathrm{C}$ for $2 \mathrm{~h}$ and storing at $-20^{\circ} \mathrm{C}$ overnight in methanesulfonic acid $(12 \mathrm{ml})$.

b Equivalent moles of prcpionic anhydride per $N$-acetylglucosamine residue.

c Propionylated groups per $N$-acetylglucosamine.

Table II. Butyrylation of chitin in a methanesulfonic acid-butyric anhydride-butyric acid mixture

\begin{tabular}{|c|c|c|c|c|c|c|c|c|c|c|}
\hline \multirow{2}{*}{$\begin{array}{c}\text { Sample } \\
\text { No. }\end{array}$} & \multirow{2}{*}{$\frac{\begin{array}{c}\text { Butyric } \\
\text { anhydride }^{\mathrm{a}}\end{array}}{\mathrm{ml}\left(\text { equiv } \mathrm{mol}^{\mathrm{b}} \text { ) }\right.}$} & \multirow{2}{*}{$\frac{\begin{array}{c}\text { Butyric } \\
\text { acid }^{\text {a }}\end{array}}{\mathrm{ml}}$} & \multirow{2}{*}{$\begin{array}{l}\text { Degree of } \\
\text { butyrylation }\end{array}$} & \multirow{2}{*}{$\frac{\text { Yield }}{\%}$} & \multicolumn{3}{|c|}{ Found $/ \%$} & \multicolumn{3}{|c|}{ Calcd $/ \%$} \\
\hline & & & & & $\mathrm{C}$ & $\mathrm{H}$ & $\mathbf{N}$ & $\mathrm{C}$ & $\mathrm{H}$ & $\mathrm{N}$ \\
\hline 1 & - & 18.0 & 0.3 & 82 & 47.31 & 7.06 & 6.16 & 47.38 & 6.83 & 6.01 \\
\hline 2 & $2.3(1.0)$ & 15.7 & 0.4 & 85 & 47.96 & 7.03 & 5.97 & 47.99 & 6.88 & 5.83 \\
\hline 3 & $4.6(2.0)$ & 13.4 & 1.0 & 93 & 51.48 & 7.17 & 5.23 & 51.06 & 7.14 & 4.96 \\
\hline 4 & $6.9(3.0)$ & 11.1 & 1.5 & 97 & 53.81 & 7.47 & 4.47 & 53.75 & 7.25 & 4.48 \\
\hline 5 & $9.2(4.0)$ & 8.8 & 1.6 & 99 & 54.05 & 7.37 & 4.23 & 54.23 & 7.27 & 4.39 \\
\hline 6 & $18.0(7.8)$ & - & 1.8 & 94 & 55.08 & 7.56 & 4.03 & 55.13 & 7.31 & 4.23 \\
\hline 7 & $1.2(0.5)$ & - & 0.1 & 45 & 46.20 & 6.83 & 6.27 & 46.02 & 6.71 & 6.39 \\
\hline
\end{tabular}

a, b, c See Table I. 
Table III. Formylation of chitin in a methanesulfonic acid-formic acid mixture

\begin{tabular}{|c|c|c|c|c|c|c|c|c|c|}
\hline \multirow{2}{*}{$\begin{array}{l}\text { Sample } \\
\text { No. }\end{array}$} & \multirow{2}{*}{$\frac{\text { Formic acid }^{\mathrm{a}}}{\mathrm{ml}\left(\text { equiv } \mathrm{mol}^{\mathrm{b}} \text { ) }\right.}$} & \multirow{2}{*}{$\begin{array}{c}\text { Degree of } \\
\text { formylation }^{c}\end{array}$} & \multirow{2}{*}{$\frac{\text { Yield }}{\%}$} & \multicolumn{3}{|c|}{ Found $/ \%$} & \multicolumn{3}{|c|}{ Calcd $/ \%$} \\
\hline & & & & $\mathrm{C}$ & $\mathrm{H}$ & $\mathrm{N}$ & $\mathrm{C}$ & $\mathrm{H}$ & $\mathrm{N}$ \\
\hline 1 & $0.3(0.5)$ & 0.4 & 44 & 45.33 & 6.38 & 6.29 & 45.16 & 6.32 & 6.27 \\
\hline 2 & $0.5(1.0)$ & 0.6 & 62 & 45.08 & 6.31 & 5.95 & 45.10 & 6.16 & 6.12 \\
\hline 3 & $2.7(5.0)$ & 1.0 & 88 & 45.00 & 5.91 & 5.77 & 45.66 & 5.93 & 5.86 \\
\hline 4 & $5.3(10.0)$ & 1.3 & 86 & 45.66 & 5.93 & 5.86 & 45.42 & 5.61 & 5.70 \\
\hline 5 & $18.0(33.8)$ & 1.4 & 77 & 45.87 & 5.98 & 5.83 & 45.56 & 5.53 & 5.65 \\
\hline
\end{tabular}

a, b, c See Table I.

ture gave almost completely propionylated chitin (1.9 propionylchitin, or $95 \%$ propionylated chitin). On the other hand, the reaction in methanesulfonic acid-propionic acid mixture gave 1.0 propionylchitin $(50 \%$ propionylated chitin). The procedure employing the use of propionic acid and propionic anhydride mixture gave propionylchitin having from 1.0 to 1.9 degrees of substitution, as shown in Table I (No. 2-No. 6). Also, propionylchitin with a low degree of substitution could be prepared by using a small calculated amount of propionic anhydride without the addition of propionic acid, as shown by No. 8 in Table I.

Chitin derivatives with different degrees of butrylation were also prepared similarly, using butyric acid and butyric anhydride as shown in Table II. A derivative having up to 1.8 degrees of substitution could be prepared readily.

Recently, Ando and Kataoka reported a detailed study on the acylation reactions of chitin. ${ }^{5}$ These workers prepared many derivatives of acylchitin such as propionylchitin, butyrylchitin, hexanoylchitin, and decanoylchitin, using a trichloroacetic acid-1,2-dichloroethane mixture with the addition of the corresponding carboxylic anhydride. This method has the advantage of simplicity but has a practical limitation of incomplete substitution because of the relatively lower acid strength of trichloroacetic acid compared with methanesulfonic acid. In the case of the methanesulfonic acid procedure, a higher degree of substitution could be attained. In this case, the acylation reaction can proceed under homogeneous conditions, thereby promoting a higher degree or virtually complete acylation reaction. Also, this method has the practical advantage of simplicity and universal application for preparing different acylchitin de- rivatives. The preparation of acylchitin from alkali chitin has a practical limitation since the degree of substitution is usually unsatisfactorily low.

\section{Preparation of Formylchitins}

The preparation of formylchitin cannot be performed in the same way as in the case of acetylchitin, propionylchitin or butyrylchitin, because formic anhydride is not stable. Formyl chloride as a reagent for the formylation is also stable only at very low temperatures. Hence, formylation had to be carried out only in a formic acid-methanesulfonic acid mixture and the results are listed in Table III. Although variously substituted formylchitins could be easily prepared by this method, the highest degree of substitution achieved was 1.4. Reformylation of the formylated chitin did not give any product of higher degree of formylation. The formylation reaction in concentrated sulfuric acid was also attempted, expecting a better degree of formylation, since the acidity of sulfuric acid is higher than that of methanesulfonic acid. However, this result was not any better since the degree of substitution attained was only 1.1 . The reaction in methanesulfonic acid seems to be better and formylchitin with the degree of substitution of up to 1.4 can be readily prepared by this method.

Viscosity Change of Chitin in Methanesulfonic Acid

The use of strong acids as reagents in the acylation reactions of chitin can cause considerable decomposition of chitin. In order to estimate roughly the degree of decomposition of chitin in methanesulfonic acid, the time course curves of the viscosity change of the chitin solution were observed at various temperatures as shown in Figure 1. The viscosity change at $40^{\circ} \mathrm{C}$ is very rapid and reaches 


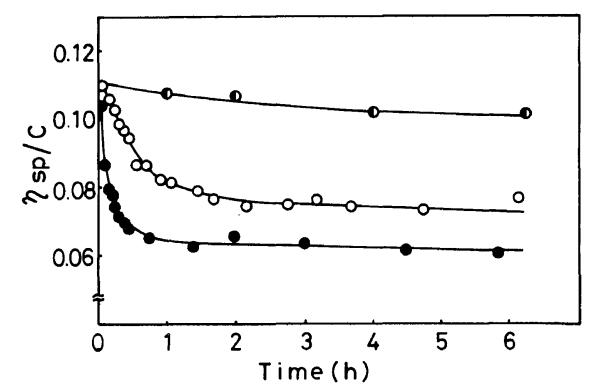

Figure 1. The viscosity change of a chitin solution of methanesulfonic acid at $0^{\circ} \mathrm{C}(\mathrm{O}), 25^{\circ} \mathrm{C}(\mathrm{O})$, and $40^{\circ} \mathrm{C}$ (O).

almost a constant value in less than an hour. The viscosity falls significantly rapidly even at $25^{\circ} \mathrm{C}$ but at $0^{\circ} \mathrm{C}$, the temperature usually employed for the acylation of chitin, very little viscosity change was observed. Consequently, the acylated chitin derivatives reported in this study do not seem to undergo any serious decomposition during the reaction in methanesulfonic acid.

\section{Infrared Absorption Spectra}

The infrared absorption spectra of acylated chitins of the highest degree of substitution, 1.4 formylchitin, 1.9 propionylchitin, and 1.8 butyrylchitin, are shown in Figure 2 with that of chitin itself. On proceeding with the acylation, the new absorptions at $1740 \mathrm{~cm}^{-1}$ and around $1200 \mathrm{~cm}^{-1}$, characteristic of the esters of fatty acids, appeared with the corresponding decrease in the absorptions at 1270,1110 , and $3400 \mathrm{~cm}^{-1}$ which are due to the hydroxyl group. Furthermore, the absorptions due to aliphatic-methylene chain also appeared at 2925 , 2850 , and $800 \mathrm{~cm}^{-1}$ in propionylchitin, and 2925 , 2850, 790, and $740 \mathrm{~cm}^{-1}$ in butyrylchitin, respectively.

\section{The Solubility Properties}

Formylchitin, propinonylchitin, and butyrylchitin were all easily soluble in the acidic solvents such as formic acid or dichloroacetic acid as in the case of acetylchitin reported previously. ${ }^{1}$ Highly butyrylated chitin showed very good solubility properties in common organic solvents. For instance, 1.8 butyrylchitin is easily soluble in dioxane, tetrahydrofuran, acetone, acetonitrile, dimethylformamide, acetic acid, and methanol, forming a clear and viscous solutions. This good solubility

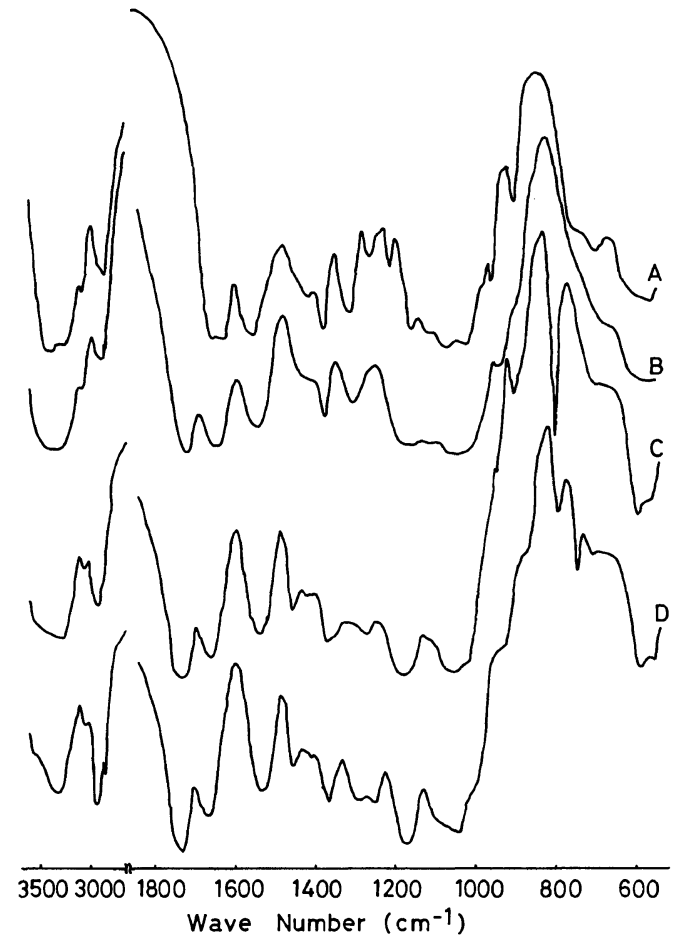

Figure 2. Infrared absorption spectra of chitin and acylchitins: A, chitin; B, 1.4 formylchitin; C, 1.9 propionylchitin; D, 1.8 butyrylchitin.

property should enhance the general utilization of chitin. The suitability of various acylchitin derivatives for industrial and biomedical use is currently under investigation at our laboratory.

Acknowledgement. The authors should like to express their appreciation to Dr. Junzo Noguchi, Professor Emeritus of Hokkaido University, for his valuable advice, and to Nippon Suisan Co. Ltd. for their support.

\section{REFERENCES}

1. N. Nishi, J. Noguchi, S. Tokura, and H. Shiota, Polym. J., 11, 27 (1978).

2. O. Somorin, N. Nishi, S. Tokura, and J. Noguchi, Polym. J., 11, 391 (1978).

3. S. Tokura, N. Nishi, O. Somorin, and J. Noguchi, Polym. J., 12, 687 (1980).

4. T. Komai, K. Kaifu, N. Nishi, J. Noguchi, and M. Nakazono, Preprints, The 8th Symposium on Biomedical Polymers, The Society of Polymer Science, Japan, Kyoto, November 21, 1978, p 21.

5. T. Ando and S. Kataoka, Kobunshi Ronbunshu, 37, 1 (1980). 